
\title{
Impact of Macronutrients Intake on Weight Loss among Obese Adolescent College Girls in Erode
} Taluk

\author{
S. Anuradha ${ }^{1 *}$ and V. Raji Sugumar ${ }^{2}$ \\ 'Associate Professor, Department of Nutrition and Dietetics, Vellalar College for Women, Erode, Tamilnadu, India; \\ anusai1986@gmail.com \\ ${ }^{2}$ Associate Professor, Department of Home Science, Avvaiyar Government College for Women, Karaikal, UT of Pu- \\ ducherry, India; rajis207@gmail.com
}

\begin{abstract}
This study was set to analyse the impact of micronutrient intake on weight loss among college going adolescent girls in Erode Taluk located in the western part of Tamilnadu. Based on the International Standards of Body Mass Index four categories of obesity levels each comprising of 25 subjects was selected from the total of 567 obese subjects. The four BMI classifications were BMI-I (25-29), BMI-II (30-32), BMI-III (32.50-34) and BMI-IV (35-40). Using 24 hours recall method details on food consumed on a normal working day was recorded. Based on the information provided the subjects were counseled for diet modification i.e., foods should be rejected, restricted and replaced. The results showed that the intake of total calories, carbohydrates and fat before and after the intervention was found to be significant at $1 \%$ level where as protein intake was not significant. After six months period the weight loss was found to be $4.92 \mathrm{Kg}$ (BMI-I), $5.78 \mathrm{Kg}$ (BMIII), 5.12Kg (BMI-III) and 5.09Kg (BMI-IV). This study concluded that culturally sensitive counseling, promoting a balanced diet and increase in physical activities renders the obese adolescents to control weight gain in a slow and steady pattern.
\end{abstract}

Keywords: Adolescents, Micronutrient, Obesity, BMI

\section{Introduction}

Transition period of adolescence lies between childhood and adulthood. The period of adolescence vary widely depending on the tradition, culture and social factor within each society. According to Flegal et al (2002) ${ }^{3}$ Obesity is among our Nation's most pressing public health problem WHO has declared obesity as a global Epidemic. It has been reported that about 30 per cent of our population today is found to be obese ${ }^{3}$. Obesity is a common eating disorder associated with adolescence. The condition can lead to social disabilities and unhappiness which may cause stress and even mental illness ${ }^{5}$. To curtail this obese condition in the adolescent stage itself, this study intervened dieting among obese adolescent college girls to bring out weight loss after six months of study period.

\section{Objectives of the Study}

- To intervene rejection, restriction and replacement diet therapy.

- To correlate the weight loss due to diet intervention.

\section{Methodology}

Erode Taluk with ten colleges selected for this study comprising of 567 subjects study General information such as family background, social status, economical status educational status and dietary pattern were collected for 567 subjects and they were categorized, based on as BMI-I (25.29.99), BMI-II(30.32.49), BMI-III (32.50-34.99) and BMI-IV (35-39-99). Diet intervention was followed by

${ }^{*}$ Author for correspondence 
rejected restricted and replaced food therapy by using diet manual and 24 hours recall method. Twenty five subjects in each BMI category, totally 100 subjects were selected for this study.

Macro nutrients such as energy carbohydrates, protein, fat and fiber were determined before and after diet intervention. The data was collected and statistical methods such as standard deviation, ' $\mathfrak{t}$ ' test, study of significance of correction and analysis of variance (Anova) were employed.

\section{Results and Discussion}

Diet manual supplied to the subjects who demonstrated the standardized food allowances, rejected, restricted and replaced diet protocol and a week cyclic menu. The impact was noticed and the table I explains the macro nutrient intake before and after diet intervention.

From the above Table, it was evident that all macronutrients were found to be reduced. Regarding carbohydrate consumption before intervention, the range was $420-450 \mathrm{~g}$ which was declined to the range of $350-400 \mathrm{~g}$ in all BMI ranges, the protein intake was found to be the same and no significant difference was observed. Adopting vegetarian

Table 1. Mean macronutrients intake before and after diet intervention

\begin{tabular}{|c|c|c|c|c|c|c|c|c|c|}
\hline \multirow{2}{*}{ S.No } & \multirow{2}{*}{ NUTRIENTS } & \multirow{2}{*}{ BMI } & \multicolumn{3}{|c|}{ BDEIN } & \multicolumn{3}{|c|}{ ADEIN } & \multirow{2}{*}{ 't' value } \\
\hline & & & Mean & S.D & S.E & Mean & S.D & S.E & \\
\hline \multirow{4}{*}{1} & \multirow{4}{*}{ Total Calories (kcal) } & I & 2664.70 & 8.05 & 2.54 & 2461.30 & 4.92 & 1.55 & 80.79ه内 \\
\hline & & II & 2711.50 & 4.97 & 1.57 & 2509.90 & 6.50 & 2.05 & $70.38 \times$ \\
\hline & & III & 2820.20 & 3.42 & 1.08 & 2634.50 & 3.62 & 1.14 & 80.79ه内 \\
\hline & & IV & 2901.50 & 5.08 & 1.60 & 2700.00 & 4.52 & 1.42 & $180.22 \mathbb{\square}$ \\
\hline \multirow{4}{*}{2} & \multirow{4}{*}{ Carbohydrates (g) } & I & 442.60 & 6.56 & 2.07 & 365.10 & 5.25 & 1.66 & $27.08 \times \square$ \\
\hline & & II & 424.50 & 3.02 & 0.95 & 399.10 & 4.12 & 1.30 & $32.42 \mathbb{\square}$ \\
\hline & & III & 429.90 & 3.66 & 1.15 & 399.90 & 5.25 & 1.66 & $27.08 \mathrm{\square}$ \\
\hline & & IV & 444.50 & 3.02 & 0.95 & 404.90 & 3.47 & 1.10 & $25.07 \mathrm{Q}$ \\
\hline \multirow{4}{*}{3} & \multirow{4}{*}{ Protein $(\mathrm{g})$} & I & 89.36 & 5.10 & 1.61 & 90.40 & 3.06 & 0.96 & $0.77 \mathrm{NS}$ \\
\hline & & II & 93.70 & 2.00 & 0.63 & 94.90 & 3.03 & 0.95 & $0.98 \mathrm{NS}$ \\
\hline & & III & 99.30 & 7.11 & 2.25 & 95.00 & 2.58 & 0.81 & $0.77 \mathrm{NS}$ \\
\hline & & IV & 100.30 & 4.94 & 1.56 & 99.60 & 3.20 & 1.01 & $0.28 \mathrm{NS}$ \\
\hline \multirow{4}{*}{4} & \multirow{4}{*}{ Fat (g) } & I & 59.80 & 3.22 & 1.01 & 54.60 & 3.13 & 0.99 & $3.24 \mathrm{WD}$ \\
\hline & & II & 74.30 & 2.94 & 0.93 & 54.00 & 2.66 & 0.84 & $17.01 \mathrm{Q}$ \\
\hline & & III & 73.90 & 2.60 & 0.82 & 49.80 & 4.02 & 1.27 & $3.24 \mathrm{QX}$ \\
\hline & & IV & 80.30 & 3.33 & 1.05 & 60.50 & 3.02 & 0.95 & $30.63 凶 \square$ \\
\hline \multirow{4}{*}{5} & \multirow{4}{*}{ Fiber (g) } & I & 10.50 & 2.06 & 0.65 & 40.30 & 3.33 & 1.05 & 24.45区 \\
\hline & & II & 14.80 & 3.32 & 1.05 & 44.50 & 3.02 & 0.95 & $22.84 \bowtie$ \\
\hline & & III & 10.40 & 3.20 & 1.01 & 40.20 & 3.42 & 1.08 & $24.45 \mathrm{QD}$ \\
\hline & & IV & 10.20 & 3.42 & 1.08 & 40.20 & 3.42 & 1.08 & $42.90 \mathbb{\square}$ \\
\hline
\end{tabular}

BDEIN - Before Diet and Exercise Intervention ADEIN - After Diet and Exercise Intervention W Significant at $1 \%$ level N.S - Not Significant 
or modified vegetarian diet has beneficial effects on body weight and health. This study also recommended plant foods which have lower fat and carbohydrate contents 4 .

Regarding fat consumption of the subjects, ranged from $60 \mathrm{~g}$ to $80 \mathrm{~g}$ per day. After intervention the range was reduced to $50 \mathrm{~g}$ to $60 \mathrm{~g}$ in all $\mathrm{BMI}$ groups. The statistical analysis revealed that the fat consumption was found to be significant at $1 \%$ level in all BMI groups. The reduction of at content showed that subjects were following the intervention properly. Astrup et al.1 (1997)suggested that when the fat content of diet is reduced to $20-25$ per cent of calories people trend to loose weight regardless of whether they decreases their calorie intake too ${ }^{1}$.

According to fiber consumption, the range was increased from $10 \mathrm{~g}-14 \mathrm{~g}$ to $40 \mathrm{~g}-44 \mathrm{~g}$. It promotes satiety and may increase energy losses. Hence the weight loss was noticed among the selected subjects. Figure 1 shows the macronutrient intake before and after intervention.

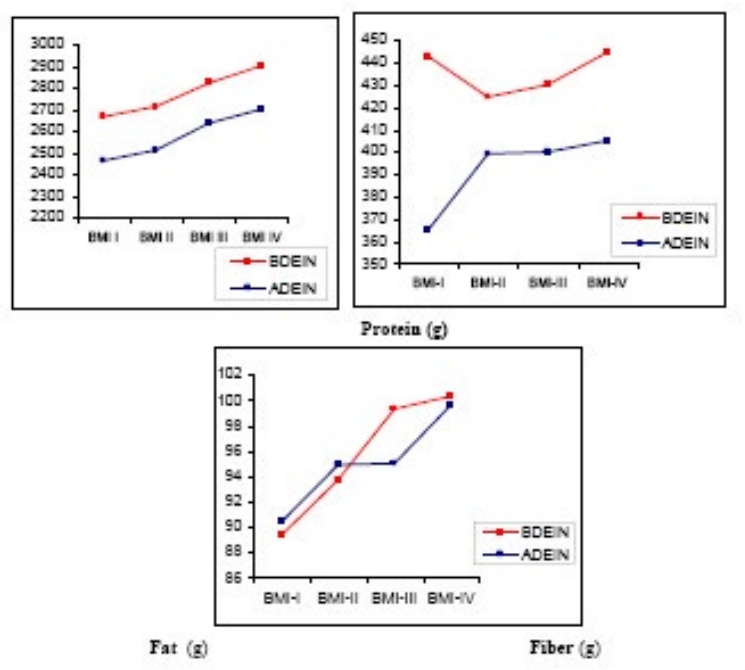

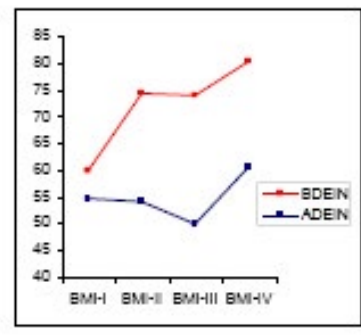

Total Calorien (K. Cal)

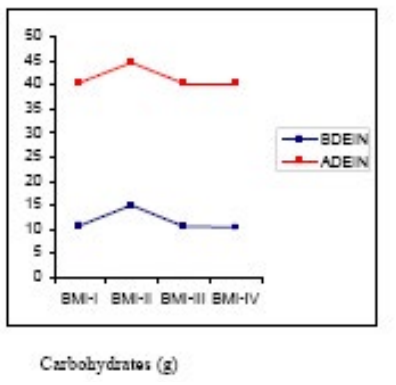

Cabohydratos (g)
Figure 1. Macronutrient intake before and after diet intervention
Table 2. Weight loss during the study period

\begin{tabular}{|c|c|c|c|c|c|c|c|}
\hline \multirow{2}{*}{ S.NO } & \multirow{2}{*}{$\begin{array}{c}\text { BMI } \\
\text { Range }\end{array}$} & \multicolumn{5}{|c|}{ Duration in months (Weight loss in kg) } \\
\cline { 3 - 8 } & & One & Two & Three & Four & Five & Six \\
\hline 1 & BMI-I & 0.670 & 1.620 & 2.330 & 3.130 & 4.020 & 4.920 \\
\hline 2 & BMI-II & 1.010 & 1.860 & 2.410 & 3.460 & 4.910 & 5.780 \\
\hline 3 & BMI-III & 0.990 & 1.860 & 2.960 & 3.510 & 4.120 & 5.120 \\
\hline 4 & BMI-IV & 0.950 & 1.840 & 2.110 & 3.360 & 4.070 & 5.090 \\
\hline
\end{tabular}

\section{Effect of Diet Intervention on Weight Loss of the Selected Subjects}

The effective measures used in this study, rejected, restricted and replaced diet therapy brought a significant weight loss among the selected subjects. Table 2 explains the weight loss due to diet intervention. The weight loss ranged from $0.670 \mathrm{~kg}$ to $5.090 \mathrm{~kg}$ up to 6 months in all BMI groups.

Regarding significance of correlation diet and weight loss was found to be positively correlated since rejected and restricted diet therapy reduces the weight of the subjects.

\section{Conclusion}

Adolescent obesity among college girls calls for appropriate screening and management. The methods are not enough to overcome this risk. Hence this study was conducted and concluded as follows.

Obese condition among college girls aged 17-21.5 years is related to familial and environmental factors, including incorrect eating habits, more frequency in dining in fast food restaurants, parties and functions. The replacement of soft drinks and other sugar containing beverages such as fruit juices by non- calorie alternatives seem to be a promising approach for the prevention of overweight among adolescents ${ }^{6}$. Dietary treatment consisting in the lowering of energetic value of the diet through rejection, restriction and replacement diet therapy and was more effective in the selected subjects. Finally from this study it was concluded that culturally sensitive counseling, promoting a balanced diet and increasing physical activity 
would maintain the optimum BMI range among adolescent college girls 2 .

\section{References}

1. Astrup A, Toubro S, Raben A, Skov AR. The role of low fat diets and fat substitutes in body weight management. Journal of the American Dietetic Association. 1997; 7(suppl):82-7.

2. Berkey CS, Rockett HR, Field AE, Gillman MW, Colditz GA. Sugar added beverages and adolescent weight change. Obesity Research. 2004; 12:778-88. PMid:15166298. https://doi.org/10.1038/oby.2004.94

3. Flegal KM, Arroll MD, Ogden CL. Johnson CL. Prevalence and trends in obesity among U.S. adults, 1999-2000. JAMA.
2002; 288:1723-7. PMid:12365955. https://doi.org/10.1001/ jama.288.14.1723

4. Garrow JS. Very low calorie diets should not be used. International Journal of obesity. 1989; 13(suppl 2):145-7. PMid:2693379.

5. Ludwing. Complications of childhood obesity. The New England Journal of Medicine. 2007; 357(23):2325.

6. Philipps SM, Badini LG, Naumova En, Cyr H, Colclough S, et al., (2004). Energy dense snack food intake in adolescence longitudinal relationship to weight and fatness. Obeisty Research. 12; 461-72. https://doi.org/10.1038/ oby.2004.52

7. WHO (2003) Obesity: Prevention and management of the world epidemic technical report No.916; Geneva. 